\title{
Analysis of Gas Content and Permeability Change Pattern of a Coal Reservoir in the Tectonic Positions Based on a THM Coupled Model
}

\author{
Zhenni Ye $\mathbb{D}^{1,2,3}$ Enke Hou, ${ }^{2}$ Huantong Li, ${ }^{2}$ Zhonghui Duan, ${ }^{3}$ and Fan $\mathrm{Wu}^{4}$ \\ ${ }^{1}$ College of Civil Engineering and Architecture, Hainan University, Haikou Hainan 570228, China \\ ${ }^{2}$ College of Geology and Environment, Xi'an University of Science and Technology, Xi'an 710054, China \\ ${ }^{3}$ Key Laboratory of Coal Resources Exploration and Comprehensive Utilization, Ministry of Natural Resources, Xi'an 710021, China \\ ${ }^{4}$ School of Emergency Management and Safety Engineering, China University of Mining and Technology (Beijing), \\ Beijing 100083, China
}

Correspondence should be addressed to Zhenni Ye; zn.ye@hainanu.edu.cn

Received 6 January 2021; Revised 20 January 2021; Accepted 29 January 2021; Published 23 February 2021

Academic Editor: Feng Xiong

Copyright (C) 2021 Zhenni Ye et al. This is an open access article distributed under the Creative Commons Attribution License, which permits unrestricted use, distribution, and reproduction in any medium, provided the original work is properly cited.

\begin{abstract}
The theory of coalbed methane distribution controlled by tectonism is a hot issue in the field of geofluid-geotectonic interaction research. Taking the geological structure in the scale range of the 1302 working face of a Guojiahe wellfield in a Yonglong mining area as the background, this paper focuses on the basic research problem of the influence of geological structure on the control of coal reservoir gas content and uses a THM coupling model to analyze the change of coalbed gas content and distribution characteristics of different tectonic positions. The change of CBM content and permeability in the anticline, syncline, and faults is analyzed. Accordingly, the variation distance of gas content and reservoir permeability controlled by tectonism of different geological structures is quantified to provide guidance for the selection of CBM-favorable areas. The research results show that the gentle dip syncline hinge zone is a potential gas-rich area with heat preservation and low permeability, while the gentle dip anticline hinge zone is a gas-poor area with low temperature and low pressure and high permeability. The thick coal seam zone of the syncline hinge zone is the potential gas accumulation zone, and the highpermeability area is near the fault plane of a normal fault. The coal matrix near the normal fault is subjected to tensile tectonic stresses to form tensional fissures, and the coal seam in the fault plane area is susceptible to coalbed gas dispersion and increases the permeability of the coal reservoir. The variation distance of gas content and reservoir permeability controlled by the normal fault within the Guojiahe wellfield is $37 \mathrm{~m}$ and $54 \mathrm{~m}$ from the fault plane, respectively.
\end{abstract}

\section{Introduction}

The influence of geological structures on the gas content of coal seams is a hot issue in the field of interaction between geological fluids and geological structures. Therefore, it is of great theoretical significance and engineering application to study the characteristics and changes of coalbed methane (CBM) distribution under geotectonic settings. The published research results show that the "generation, accumulation, and preservation" of CBM is not only closely related to the ground stress, coal seam buried depth, and paleogeothermal and gas generation history under the control of tectonic evolution [1-6] but also influenced by the joint effect of formation pressure, lithology of surrounding rock, and microstructural characteristics of a coal reservoir [7-13], which means that when the environmental conditions such as temperature, stress, and seepage of coal reservoirs change due to tectonism, the gas content and its distribution characteristics in coal seams will change. Therefore, the deposition, generation, and preservation of CBM under the tectonism 
are the key criteria for CBM enrichment and reservoir formation, which is an important guideline for the efficient development of CBM.

The theory of CBM distribution controlled by tectonism integrates coalfield geology, gas geology, and fluid mechanics disciplines. Many domestic and foreign research results and findings have shown a close relationship between geological structure and gas content [14-16]. It is generally agreed that there is a clear pattern of CBM occurrence in a folded zone [17-19]. The results of CBM enrichment investigations in the Yangquan mining area in the Qinshui Basin, the Fuxin mining area in northeast China, the Pingdingshan mining area, and the Hancheng mining area in China all indicate that the syncline tectonic area has significant gas-rich characteristics $[16,18,20-22]$. With the great attention to the safe and efficient exploitation of coal seams in China in recent years, the technology of CBM exploitation and extraction has been developed; in particular, the basic theoretical research results on pore-fissure seepage and reservoir properties are fruitful [23-27]. In particular, numerical simulation, X-ray CT scanning, scanning, and hydraulic permeability enhancement methods have been widely used in the evaluation of reservoir properties and production enhancement technology [28-33]. However, the physical condition (temperature, permeability, reservoir structure, etc.) of a reservoir has been less considered in both CBM extraction and utilization technologies and mine gas management. In order to quantitatively study the relationship between multiphysical field changes and tectonic types in coal reservoirs, we start from considering the joint effect of temperature, stress, and seepage fields inside coal seams. In this paper, the coupled thermal-hydraulicmechanical (THM) numerical model is used to calculate the variation law of CBM content, reservoir pressure, temperature, and permeability parameters in different tectonic positions and to propose favorable conditions suitable for the efficient development of CBM in the Guojiahe wellfield, which has certain engineering research significance.

\section{Geological Structure and Gas Control Characteristics of the Study Area}

2.1. Overview of Geological Tectonics in the Study Area. The study area is located in the northern part of the Weibei flexure belt first-grade tectonic unit in the southern part of the Ordos Basin and belongs to the Binchang depression thirdgrade tectonic unit. Under the influence of the IndonianYanshanian period near north-south tectonic movement, several dip folds have been developed in the Guojiahe wellfield [12]. The axial dip direction generally extends along the north-east-east or near east-west direction, with the dip angle of both limbs ranging from 3 to $10^{\circ}$, showing a gentle dip fold tectonic pattern. There are three large-scale folds in and around the study area, namely, the Getousi anticline in the south of the wellfield, the Liangting anticline in the west, and the Caizigou-Zhangbagou syncline in the east-central part of the wellfield (Figure 1). The Jurassic structure is generally a gentle dip fold in the NE-NEE strike direction, with little variation in occurrence, accompanied by a small number of tension faults in the near east-west direction. The coal- bearing rock system of the Jurassic Yan'an group is in angular unconformity contact with the Middle Triassic strata of the Tongchuan group, and the overlying Jurassic groups have an obvious inheritance in terms of sediment thickness and sedimentary pattern. The no. 3 coal seam in the Yan'an group is the main mining coals with thickness ranges from 0.55 to $26.8 \mathrm{~m}$, with an average of $11.88 \mathrm{~m}$. The CBM content ranges from 0.17 to $5.00 \mathrm{~m}^{3} / \mathrm{t}$, with an average of $2.48 \mathrm{~m}^{3} / \mathrm{t}$ [26].

2.2. Investigation of the Gas Content of Coal Seams in the Study Area. The Guojiahe wellfield has developed a synsedimentary fold, and the coal seam in the axial part of an anticline is thin, which often does not have CBM preservation conditions. A gentle dip syncline is mostly developed in the area, and the coal seam in the axial part of a syncline is thicker, which has good conditions for gas generation; the larger the dip angle of the two limbs of the syncline, the easier it is for CBM to escape; the smaller the dip angle of the two limbs, the fracture is not developed or the reverse fault is developed, which is more favorable for CBM preservation. In the large scale of the gentle dip syncline, due to the development of normal longitudinal fault and secondary folds on both limbs, CBM is easy to escape along the faults on both limbs and the fractures at the top of the secondary anticline. Therefore, the best-preserved CBM is often located in the secondary syncline part of the syncline. In order to clarify the influence of the secondary structure on the gas content, this paper analyzes the gas content in different structural parts of the no. 33, no. 15, and no. 16 prospecting lines (as shown in (Figure 2). In prospecting line no. 33, the gas content in hole G33-5 of the axial part of the syncline is larger than that in hole G33-3 of the two limbs, larger than that in hole G33-7 of the anticline limbs with a normal fault part, and larger than that in hole G33-6 of the axial part of the anticline (Figure 2(a)). In prospecting line no. 15, the gas content of drill hole G15-3 in the deep part of both limbs of the syncline is greater than the gas content of drill hole G15-2 and drill hole X21 in the shallow part of both limbs (Figure 2(b)).

Based on the CBM preservation conditions, the anticline structure can be divided into three basic types: symmetric anticline, asymmetric anticline, and secondary anticline. In the symmetrical anticline type, the fractures at the top of large anticlines are densely developed, forming a gas transportation channel. Therefore, the axial part of the anticline's gas content tends to be poor, while the gas content becomes better in the direction of both limbs and plunging part. If the intensity of tectonic extrusion and deformation increases, leading to the development of a reverse fault system in the anticline axis, it is to a certain extent favorable to the preservation of CBM and its gas content is better. The top of the asymmetric anticline is mostly developed with tensile fractures, and the CBM is often better preserved in the slow limb because the reverse fault blocks it. The gas-bearing property of the no. 16 prospecting line in the syncline-flexureanticline with normal fault part drill hole G16-4 shown in Figure 2(c) is greater than that of the axial part of syncline X27 drill hole, which is greater than that of the gentle dip syncline limbs G16-3 drill hole and G16-5 drill hole. 


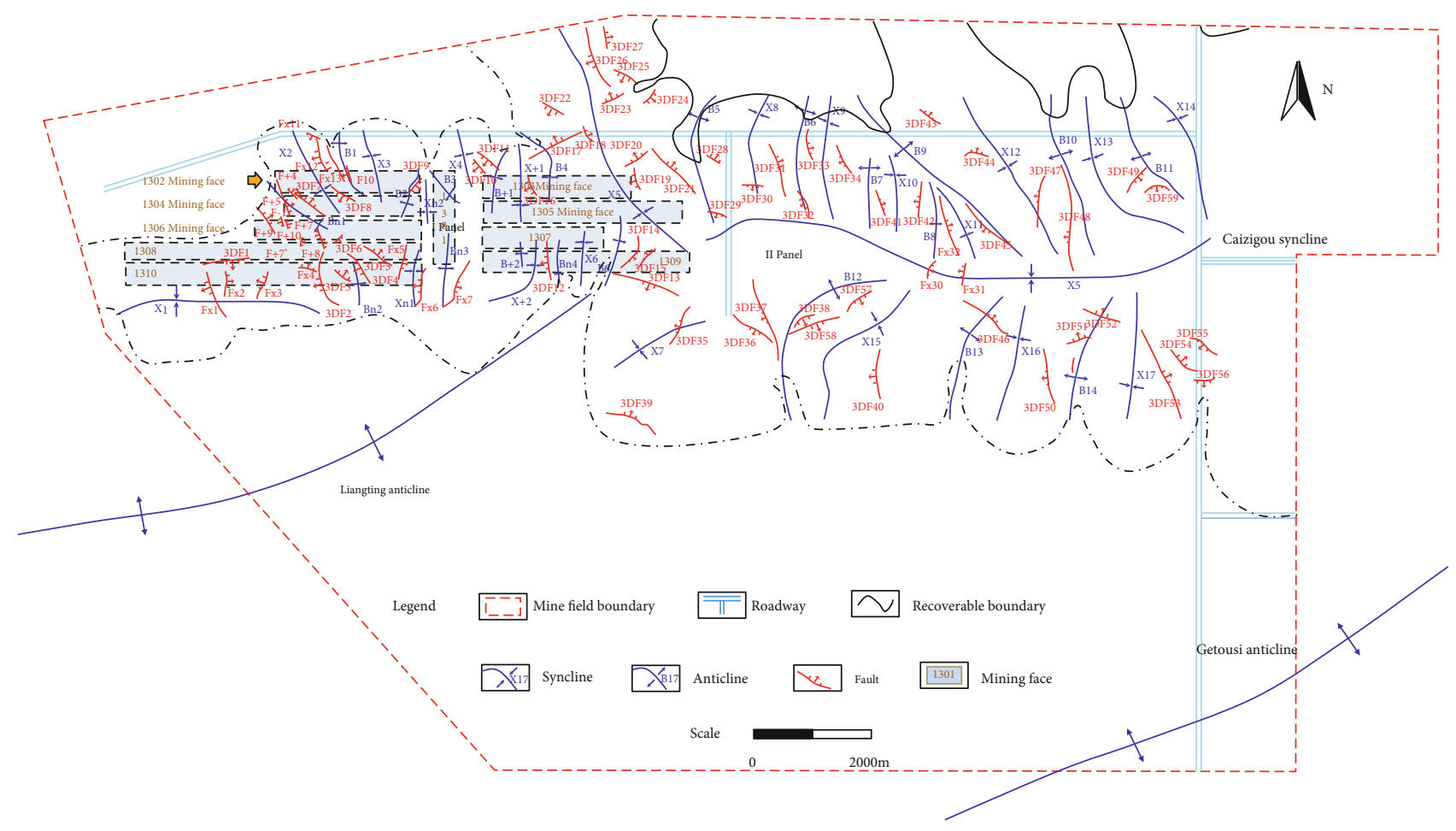

Figure 1: Geological and tectonic features of the study area.

The two limbs of the syncline or anticline develop a tensional normal fault, which destroys the coal seam's continuity. The low gas content tested in the 33-33' survey borehole shown in Figure 2(a) indicates that the methane escaped in large quantities along the fault or deteriorated the overall gas-bearing properties, resulting in a great heterogeneity in the regional distribution of gas-bearing properties.

2.3. Types of Gas-Controlling Structures in the Guojiahe Wellfield. The tectonics of the Guojiahe wellfield can be summarized as extrusion and extensional tectonics, which can be summarized into three types: gentle dip syncline, anticline and secondary anticline, and normal fault according to the combination of tectonic form and different types of tectonics. The gas content of 13 CBM boreholes in different structural parts of the three prospecting lines in the study area was analyzed (Table 1), and the influence of the structural parts on the CBM content was obtained in descending order: the deep buried part of gentle dip syncline limbs is larger than the axial part of the syncline, larger than secondary anticline limbs with a normal fault part, larger than the secondary axial part of the anticline, and larger than the slow dip shallow buried part of syncline limbs. The basic types of gas-controlling structures in the Guojiahe wellfield are divided into the shallow buried part of syncline limbs, axial part of the syncline, syncline upwarping part, intersection part of syncline and secondary syncline limbs, the syncline and secondary syncline, the axial part of the anticline and secondary anticline with a normal fault (Table 2).

\section{Establishing a Coupled Thermal-Hydraulic- Mechanical Model of CBM Distribution Controlled by Tectonism}

3.1. Mechanism of the Thermal-Hydraulic-Mechanical Model. The thermal-hydraulic-mechanical coupling relationship of CBM is studied; i.e., the distribution and change law of CBM under the interaction of the temperature field, seepage field, and stress field are considered. The methane gas in the coalbed is mainly stored on the surface of the coal matrix in the adsorbed state, and the changes of reservoir pressure and temperature affect the adsorption state of methane gas and the production of CBM. The essence of its intrinsic physical effects is the influence of ground stress, reservoir temperature, and pressure on the parameters of gas content and reservoir permeability [27, 34]. In this research, with the help of the COMSOL Multiphysics numerical software platform, a coupled thermal-hydraulic-mechanical model of CBM distribution controlled by tectonism is established. According to the physical parameters of coalbed and CBM measured in the study area, a coefficient partial differential equation (PDE) is established. Its simultaneous solution can describe the heat conduction equation and linear elastic deformation equation of CBM flowing in the coalbed [35-37]. The partial differential equations of the evolution of each physical field are listed in equations (1)-(3). The calculation should consider the flow characteristics and distribution characteristics of CBM due to the coupling effect of the thermal-hydraulic-mechanical model. 


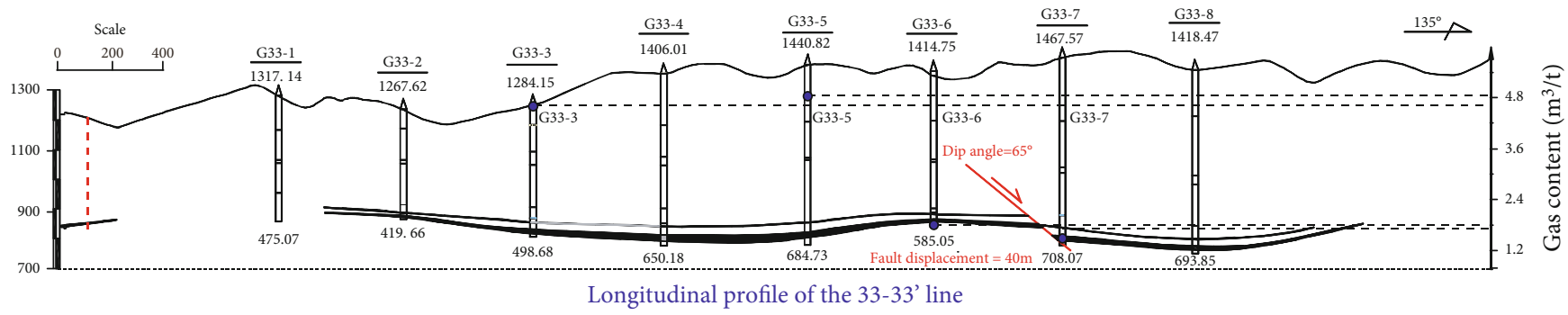

Legend

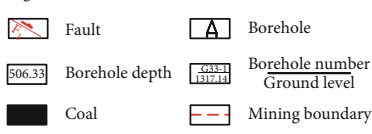

(a)

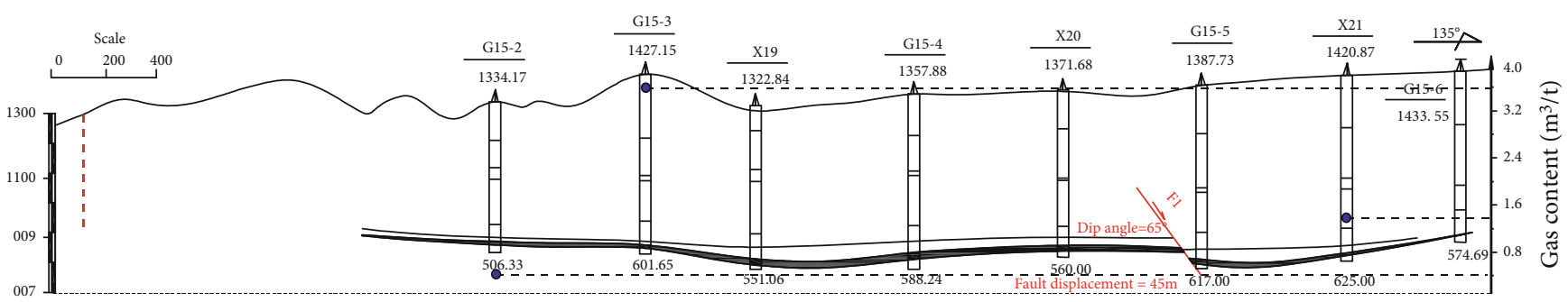

Longitudinal profile of the 15-15' line

Legend

$\triangle$ Fault $\quad \mathrm{A}$ Borehole

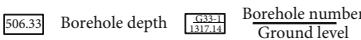

Coal $\quad F-$ Mining boundary

(b)

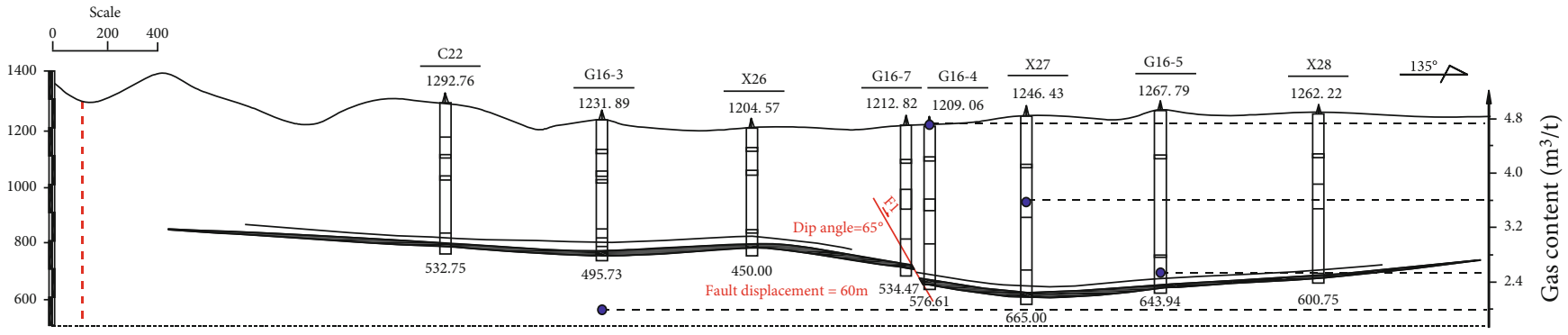

Longitudinal profile of the 16-16' line

Legend

Fault $\quad \mathrm{A}$ Borehole

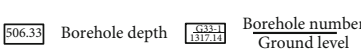

Coal $\quad-\rightarrow$ Mining boundary

(c)

Figure 2: CBM content in different geological formations revealed by exploration boreholes.

Based on the above considerations, a realistic numerical thermal-hydraulic-mechanical model of CBM is proposed, based on the following assumptions: (1) the coal matrix is an elastic porous medium composed of pores and fissures, (2) the coal matrix is compressible and conforms to the small deformation assumption, (3) the gasdynamic viscosity is not affected by temperature, (4) the $\mathrm{CBM}$ is an ideal gas and conforms to the ideal gas equation of state, (5) the matrix pore pressure in the coal of CBM is saturated, (6) the temperature of the gas at the same point is equal to the temperature of the coal matrix, and (7) the matrix pore pressure is equal to the fracture pressure [36].

The expression of the mathematical equation for the coupled temperature field of CBM in the coal matrix is

$$
\begin{aligned}
\eta \nabla^{2} T+q Q-\rho C_{V} \frac{\partial T}{\partial t}-T_{0} \theta_{T} \frac{\partial \varepsilon}{\partial t}-\theta_{\mathrm{pr}} T_{0} \\
\cdot\left[T_{0} \ln (1+b p) \frac{\partial a}{\partial T}+T_{0} \frac{a p}{1+b p}+a \ln (1+b p)\right] \frac{\partial \varepsilon}{\partial t}=0,
\end{aligned}
$$


TABLE 1: Gas-bearing characteristic of coal seams in different tectonic parts of the Guojiahe wellfield.

\begin{tabular}{|c|c|c|c|}
\hline Tectonic parts & Typical drill hole number & Borehole CBM content $\left(\mathrm{m}^{3} \cdot \mathrm{t}^{-1}\right)$ & Average CBM content $\left(\mathrm{m}^{3} \cdot \mathrm{t}^{-1}\right)$ \\
\hline \multirow{3}{*}{ Deep buried part of gentle dip syncline limbs } & G33-3 & 4.58 & \multirow{3}{*}{3.57} \\
\hline & G15-3 & 3.60 & \\
\hline & G16-5 & 2.54 & \\
\hline \multirow{4}{*}{ Axial part of the syncline } & G33-5 & 4.8 & \multirow{4}{*}{3.16} \\
\hline & G34-4 & 2.1 & \\
\hline & G16-3 & 2.08 & \\
\hline & $\mathrm{X} 27$ & 3.65 & \\
\hline \multirow{2}{*}{ Secondary anticline with normal faults } & G33-7 & 2.12 & \multirow{2}{*}{2.89} \\
\hline & G16-4 & 3.65 & \\
\hline \multirow{2}{*}{ Axial part of the secondary anticline } & G33-6 & 1.77 & \multirow{2}{*}{1.71} \\
\hline & G34-1 & 1.64 & \\
\hline \multirow{2}{*}{ Shallow buried part of gentle dip syncline limbs } & G15-2 & 0.52 & \multirow{2}{*}{0.97} \\
\hline & $\mathrm{X} 21$ & 1.42 & \\
\hline
\end{tabular}

TABLE 2: Basic types of structures controlling gas content in the Guojiahe wellfield.

\begin{tabular}{|c|c|c|}
\hline Structure type & Structure parts & Gas distribution characteristics \\
\hline \multirow{5}{*}{ Gentle dip syncline } & Shallow buried part of syncline limbs & \multirow{5}{*}{$\begin{array}{l}\text { (i) Shallow parts of both limbs are not conducive to the } \\
\text { preservation of CBM } \\
\text { (ii) Axial part of the syncline better than both limbs } \\
\text { (iii) Syncline upwarping part CBM enrichment } \\
\text { (iv) The CBM in the intersection of the main dip fold axis } \\
\text { and the larger secondary syncline is better endowed }\end{array}$} \\
\hline & Axial part of the syncline & \\
\hline & Syncline upwarping part & \\
\hline & Intersection part of the syncline & \\
\hline & and secondary syncline & \\
\hline & Axial part of anticline & \multirow{2}{*}{$\begin{array}{l}\text { (i) Low gas content in the main anticline due to the coal erosion. } \\
\text { (ii) The secondary anticline is rich in CBM, the tensional fracture } \\
\text { is developed on both limbs, the coal cover is closed, and the gas } \\
\text { content is high on both limbs }\end{array}$} \\
\hline Anticline and secondary anticline & $\begin{array}{l}\text { Secondary anticline with } \\
\text { normal faults }\end{array}$ & \\
\hline Normal fault & l & $\begin{array}{l}\text { (i) Tensional fractures with poor sealing of faults contribute to } \\
\text { the migration or escape of CBM }\end{array}$ \\
\hline
\end{tabular}

where $\eta$ is the thermal conductivity of the coal matrix $(\mathrm{J} / \mathrm{m}-\mathrm{s}-$ $\mathrm{K}), \nabla^{2}$ is the Laplace operator symbol, $T$ is the temperature variable $(\mathrm{K}), T_{0}$ is the initial temperature of the coal seam $(\mathrm{K}), Q$ is the CBM seepage velocity vector $(\mathrm{m} / \mathrm{s}), q$ is the CBM content per unit volume of methane-containing coal $\left(\mathrm{m}^{3} / \mathrm{t}\right), \rho$ is the bulk weight of coal $\left(\mathrm{kg} / \mathrm{m}^{3}\right), C_{v}$ is the specific heat capacity of coal $(\mathrm{J} / \mathrm{kg}-\mathrm{K})$, and $\theta_{T}$ is the thermal stress coefficient. Langmuir volume constant $a$ and Langmuir pressure constant $b$ are set as temperature-dependent functions $a(T)$ and $b(T)$, and $\theta_{\mathrm{pr}}$ is the stress coefficient due to CBM pressure.

It is generally accepted that adsorbed and free methane in the coal matrix obeys the modified Langmuir adsorption equilibrium equation and the state's real gas equation, respectively.

$$
q=\left(\frac{a b p c}{1+b p}+\varphi \frac{p}{p_{n}}\right) \cdot \rho_{c}
$$

where $q$ is the CBM content per unit volume of methanecontaining coal $\left(\mathrm{m}^{3} / \mathrm{t}\right) ; a$ is the Langmuir volume constant of methane in the coal matrix; $b$ is the Langmuir pressure constant of methane in the coal matrix; $c$ is the coal quality correction parameter $\left(\mathrm{kg} / \mathrm{m}^{3}\right)$, where $c=\rho g \times(100-A-M)$ $/ 100 /(1+0.31 \times M), A$ is the ash content of the coal seam (\%), and $M$ is the coal seam moisture (\%); $\varphi$ is the coal seam porosity; $p$ is the coal seam methane pressure $(\mathrm{Pa}) ; p_{n}$ is the coal seam methane gas pressure at standard atmospheric pressure $(\mathrm{Pa})$; and $\rho_{\mathrm{c}}$ is the coal seam density $\left(\mathrm{kg} / \mathrm{m}^{3}\right)$.

The mathematical equation expression for the coupled stress field in the coal reservoir is

$$
\begin{aligned}
G \sum_{j=1}^{3} \frac{\partial^{2} u_{i}}{\partial x_{j}^{2}} & +\frac{G}{1-2 v} \sum_{j=1}^{3} \frac{\partial^{2} u_{i}}{\partial x_{j}^{2}}-\theta_{T} \frac{\partial \Delta T}{\partial x_{i}}-\theta_{\text {pr. }} \frac{\partial \Delta p}{\partial x_{i}} \\
& -\theta_{\text {ads. }} a T \frac{\partial \ln (1+b p)}{\partial x_{i}}+\alpha \frac{\partial p}{\partial x_{i}}+F_{i}=0
\end{aligned}
$$

where $G$ is the Lame coefficient, $v$ is the shear modulus, $u$ is the displacement function-independent variable, $x_{i}$ and $x_{j}$ are partial differentials of displacement, and $\theta_{\text {ads }}$ is the adsorption stress coefficient of CBM, and the calculated solid stress field of coal rock in the model are considered based on the linear elastic model. 


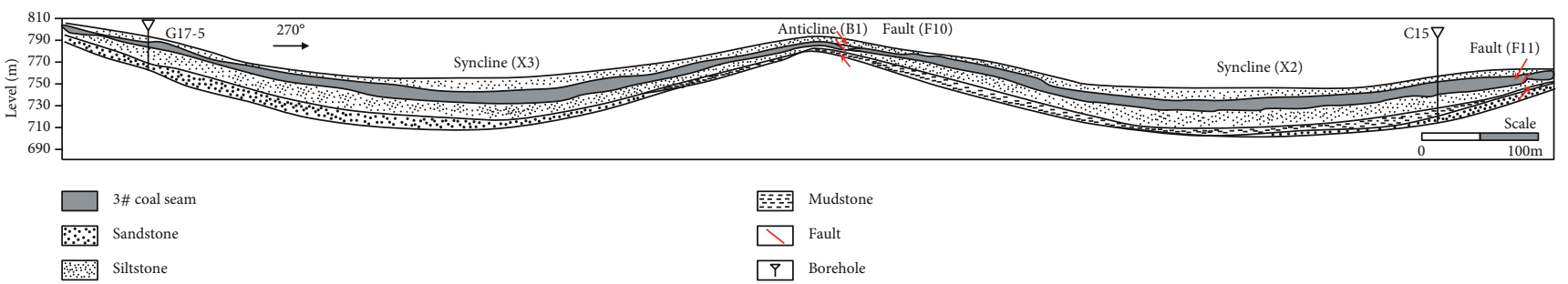

FIGURE 3: Geological section of the 1302 coal mining face.

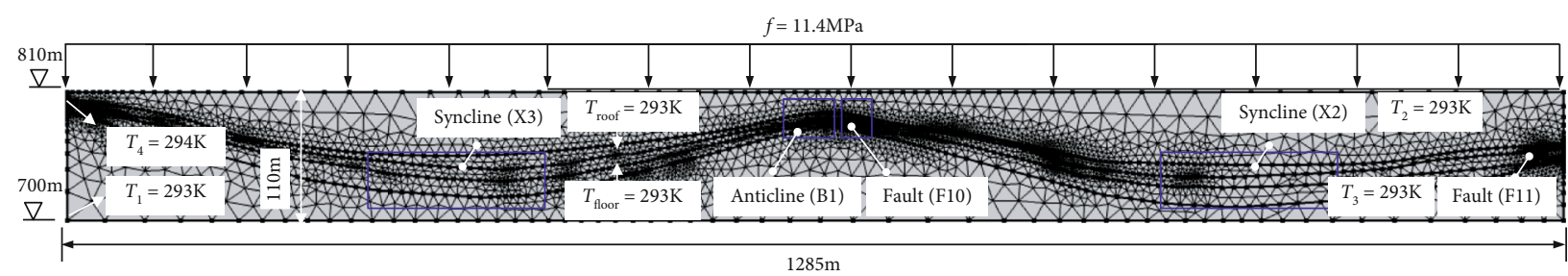

FIgURE 4: Numerical model and boundary conditions of the THM model in the 1302 coal mining face.

The mathematical equation expression of the coupled seepage field of CBM in the coal matrix considering the slip effect is

$2 \alpha p \frac{\partial \varepsilon}{\partial t}+\left[2 \varphi+\frac{2(1-\varphi)}{k_{\mathrm{s}}} p+\frac{2 a b c p_{n}}{(1+b p)^{2}}+\frac{2 a b c p_{n}}{1+b p}\right] \frac{\partial p}{\partial t}-\nabla \cdot\left(\frac{k}{u} \nabla p^{2}\right)=I$,

where $\alpha$ is the coefficient of influence of CBM on the elastic modulus of the coal matrix, $p_{n}$ is the pressure of CBM at the standard state $(\mathrm{MPa}), c$ is the elastic modulus of coal matrix material without CBM $(\mathrm{Pa}), \nabla p$ is the CBM pressure gradient within the coal seam $(\mathrm{Pa} / \mathrm{m}), I$ is the source-sink term, permeability $k$ and porosity $\varphi$ are composed of functions through strain $\varepsilon$, temperature $T(\mathrm{~K})$, and CBM pressure $p(\mathrm{~Pa})$ with a total of three independent variables, and other coupling terms are synonymous.

3.2. Original Construction Model and Numerical Model. According to the survey results of the geological structure of the no. 3 coal seam in the Guojiahe wellfield, the geological structure within the scale of the 1302 coal mining working face is selected as the research object (see Figure 3), and the numerical model of the geological structure is established as shown in Figure 4. It is determined that the coal seam's rightmost opening in the calculation model is the stopping line position, and the whole model develops the $\mathrm{X} 3$ syncline, $\mathrm{B} 1$ anticline, F10 normal fault, and F11 normal fault from the cutting hole to the stopping line direction, respectively, involving a total of three geological formations: anticline, normal fault, and syncline (Table 3 ).

The surface elevation of the 1302 coal mining working face is $+1232 \sim 1440 \mathrm{~m}$, the working face elevation is $+730 \sim 810 \mathrm{~m}$, the length is $1285 \mathrm{~m}$ on average on strike direction, the length is $270 \mathrm{~m}$ on dip direction, and the working face temperature is $293 \mathrm{~K}$. In consideration of the above working face geological conditions and mining conditions, the numerical model was designed with a length of $1285 \mathrm{~m}$, a height of $110 \mathrm{~m}$, and corresponding stratigraphic elevations of $+700 \mathrm{~m}$ to $+810 \mathrm{~m}$. The geological section of the working face was divided into planes according to the tectonic features and then imported into the COMSOL software platform for 3D model construction and triangular meshing (see Figure 4).

3.3. Basic Model Parameters. The model calculation boundary conditions are mainly based on the actual measured temperature of the working face combined with the research results on temperature boundary conditions in related studies [35, 38-40]. The initial temperature of the working face $\left(T_{1}\right)$ is $293 \mathrm{~K}$, the initial temperature of the fault hanging wall $\left(T_{2}\right)$ is $293 \mathrm{~K}$, the initial temperature of the fault footwall $\left(T_{3}\right)$ is $293 \mathrm{~K}$, the initial boundary temperature of the coal seam $\left(T_{4}\right)$ is $294 \mathrm{~K}$, and the initial boundary temperature of the coal seam roof position ( $\left.T_{\text {roof }}\right)$ is $293 \mathrm{~K}$. The initial boundary temperature of the coal seam floor boundary $\left(T_{\text {floor }}\right)$ is $293 \mathrm{~K}$. Based on the measured coal seam gas pressure of $1.70 \mathrm{MPa}$ in the extraction borehole at the working face, the overlying rock layer load $f$ of the 1302 working face is $11.4 \mathrm{MPa}$ calculated according to the vertical principal stress equation. According to Guojiahe mine rock and gas basic parameter report, physical parameters such as density, elastic modulus, Poisson's ratio of coal, and those of CBM (density, gas pressure in a standard state, and molar volume) were determined, as listed in Table 4. A triangular mesh dissects the model with a calculation error of 0.0001 , and the time is set to $150 \mathrm{~d}$.

\section{Analysis of Gas Content and Permeability of Coal Reservoirs in Different Tectonic Positions}

4.1. Simulation Analysis of CBM Distribution Controlled by Tectonism. As shown in Figure 5, the multiphysical field characteristics of the geological structure within the scale of the 1302 working face are calculated according to the 
TABLE 3: Main parameters of the geological structure of the 1302 coal mining working face.

\begin{tabular}{lcccc}
\hline Structure type & Axis extension direction $\left(^{\circ}\right)$ & Dip angle $\left(^{\circ}\right)$ & Drop $(\mathrm{m})$ & Extension length $(\mathrm{m})$ \\
\hline X3 syncline & $100^{\circ} \sim 110^{\circ}$ & $10^{\circ}$ on the west limb, $17^{\circ}$ on the east limb & N/A & 283 \\
B1 anticline & $110^{\circ} \sim 120^{\circ}$ & West limb $9^{\circ}$, east limb $10^{\circ}$ & N/A & 300 \\
F10 fault & $160^{\circ}$ & $26 \sim 60^{\circ}$ & 6 & 429 \\
X2 syncline & $110^{\circ} \sim 120^{\circ}$ & West limb $10^{\circ}$, east limb $9^{\circ}$ & N/A & 303 \\
F11 fault & $25^{\circ}$ & $55 \sim 70^{\circ}$ & 2.2 & 50 \\
\hline
\end{tabular}

TABLE 4: Main parameters of 1302 coal mining face modeling.

\begin{tabular}{|c|c|c|c|}
\hline Parameter name & Variables & Numerical value & Unit \\
\hline Coalbed gas dynamic viscosity coefficient & $\mu$ & $1.087 \times 10^{-5}$ & $\mathrm{~Pa}-\mathrm{s}$ \\
\hline Initial porosity of the coal seam & $\varphi_{0}$ & 0.0792 & I \\
\hline Rock modulus of elasticity & $E_{\mathrm{r}}$ & 30,000 & $\mathrm{MPa}$ \\
\hline Modulus of elasticity of the coal matrix & $E_{\mathrm{c}}$ & 14000 & $\mathrm{MPa}$ \\
\hline Coal Poisson's ratio & $v$ & 0.27 & I \\
\hline Coefficient of volumetric thermal expansion of coal & $\alpha_{T}$ & $0.116 \times 10^{-3}$ & $\mathrm{~m}^{3} /\left(\mathrm{m}^{3-\mathrm{K}}\right)$ \\
\hline Working surface gas pressure & $P_{0}$ & 0.1 & $\mathrm{MPa}$ \\
\hline Working surface boundary temperature & $T_{0}$ & 293 & $\mathrm{~K}$ \\
\hline Langmuir pressure constants & $P_{\mathrm{L}}$ & 3.87 & $\mathrm{MPa}$ \\
\hline Langmuir volume constants & $V_{\mathrm{L}}$ & 6.73 & $\mathrm{~cm}^{3} / \mathrm{g}$ \\
\hline Density of coal & $\rho_{\mathrm{c}}$ & 1400 & $\mathrm{~kg} / \mathrm{m}^{3}$ \\
\hline Rock density & $\rho_{\mathrm{r}}$ & 2300 & $\mathrm{~kg} / \mathrm{m}^{3}$ \\
\hline Normal gas constants & $\alpha_{T}$ & 8.3143 & $\mathrm{~J} /(\mathrm{mol}-\mathrm{K})$ \\
\hline Molar volume of coalbed methane & $V_{\mathrm{m}}$ & 0.0224 & $\mathrm{~m}^{3} / \mathrm{mol}$ \\
\hline Initial penetration rate & $k_{0}$ & $0.02 \times 10^{-15}$ & $\mathrm{~m}^{2}$ \\
\hline Ash & $A$ & 0.1622 & l \\
\hline Moisture & $M$ & 0.0835 & I \\
\hline Coal seam gas pressure at standard condition & $P_{\mathrm{g}}$ & 0.10 & $\mathrm{MPa}$ \\
\hline Coalbed gas density at standard condition & $\rho_{\mathrm{g}}$ & 0.717 & $\mathrm{~kg} / \mathrm{m}^{3}$ \\
\hline The bulk modulus of solid particles & $K_{\mathrm{s}}$ & $5.22 \times 10^{10}$ & $\mathrm{~Pa}$ \\
\hline Pore fractal dimension & $D_{\mathrm{p}}$ & 2.776 & 1 \\
\hline
\end{tabular}

thermal-hydraulic-mechanical coupling model, and it can be learned that (1) the overall CBM content $q$ is greater than $1 \mathrm{~m}^{3} / \mathrm{t}$ and the CBM content in the syncline hinge zone is higher while the CBM content near the fault plane of the normal fault is low. With the advancement of mining, the CBM content at the fault plane decreases and causes the gas content near it to decrease gradually, and the influence range gradually increases, and the change tends to be stable after $100 \mathrm{~d}$ (Figure 5(a)). (2) The overall coal reservoir pressure shows the distribution characteristics to be high in the syncline hinge zone and low near the fault plane. With the advancement of mining, the pressure difference between the syncline hinge zone, fault plane, and surrounding coal reservoir is more significant, and the influence range of coal reservoir pressure change near the fault plane gradually increases (Figure 5(b)). (3) The temperature difference of the coal reservoir is larger in different structural parts. The syncline hinge zone is the high-temperature zone of the coal reservoir, the temperature of the syncline limb gradually decreases, the temperature near the fault plane is lower, and the range of low-temperature zone near the fault plane gradually increases as the mining advances (Figure 5(c)). (4) The overall coal reservoir permeability is low, about $1.88 \times 10^{-5}$ $\mu \mathrm{m}^{2}$, the syncline hinge zone reservoir permeability is small, and the permeability near the fault plane is large. With the advance of mining, the coal reservoir permeability near the fault is higher and tends to increase with the change of time (Figure 5(d)).

In order to further study the control effect of folds and faults on the CBM content, the X3 gentle dip syncline, B1 anticline, F10 normal fault, and F11 normal fault were selected in the numerical calculation model of the 1302 coal 


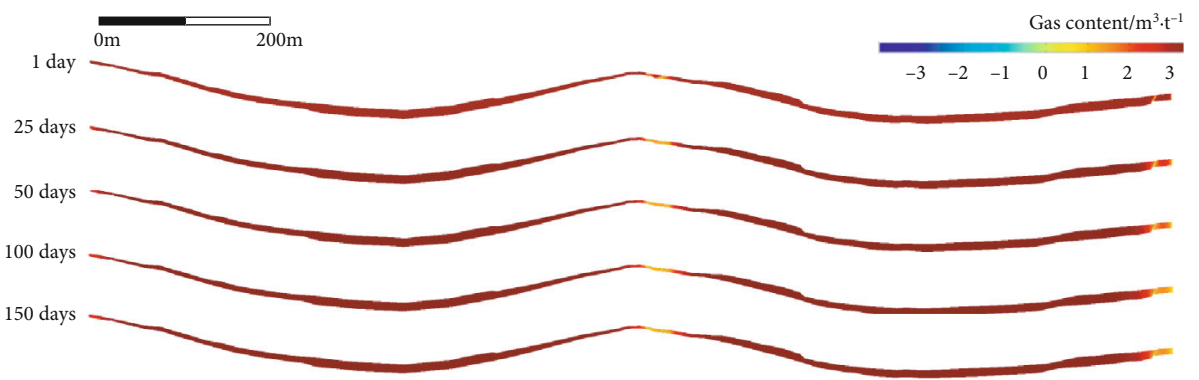

(a)

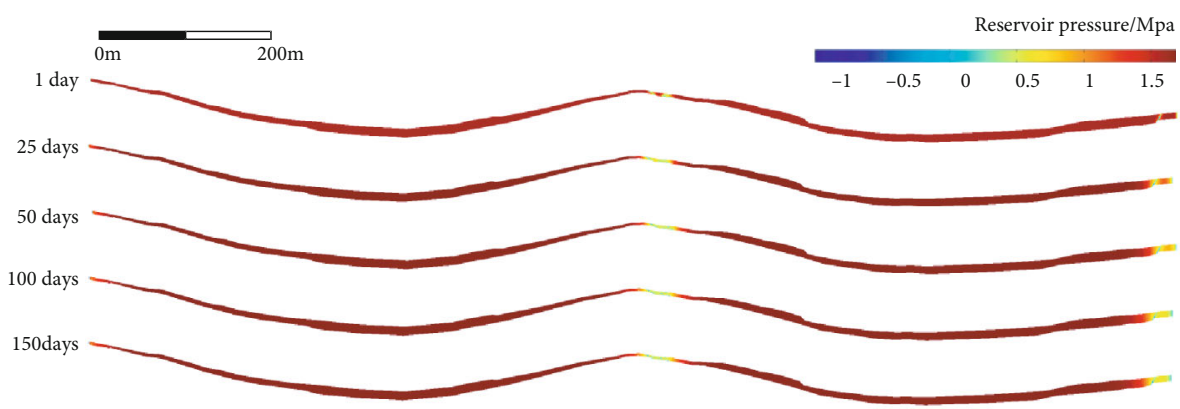

(b)

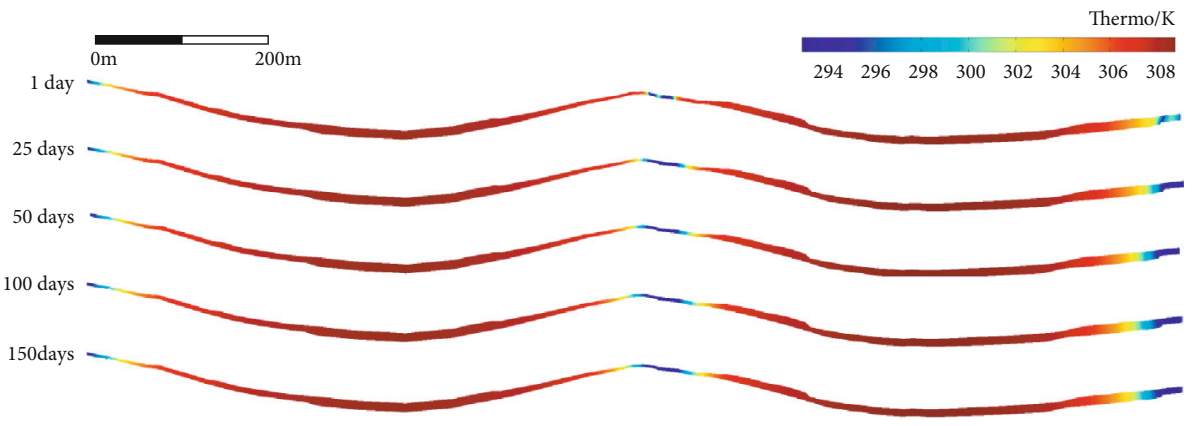

(c)

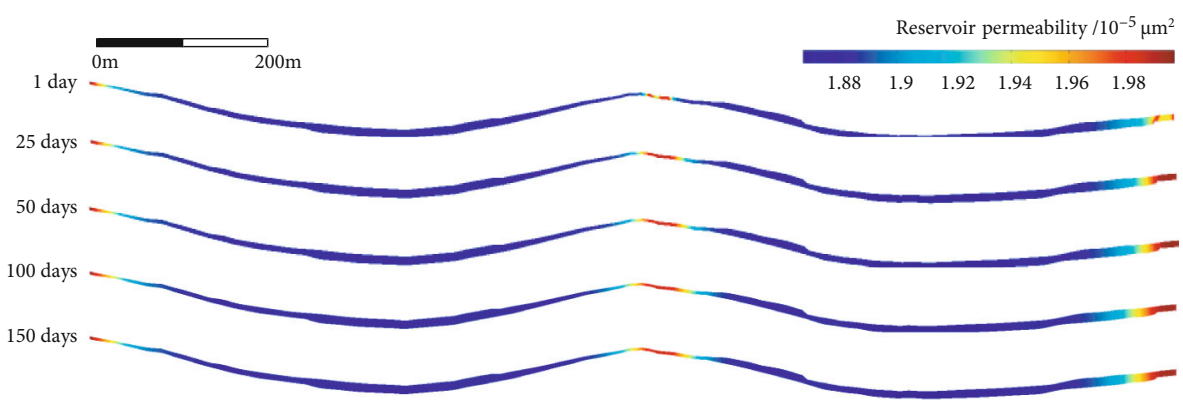

(d)

FIgURE 5: Variation of multiphysical fields in different tectonic positions: (a) CBM content; (b) coal reservoir pressure; (c) coal reservoir temperature; (d) coal reservoir permeability.

mining face to monitor the evolution law of the temperature field, seepage field, and stress field by using a twodimensional cut-off line. The length of the monitoring line near the structure is $180 \mathrm{~m}$ (direction: limb $\rightarrow$ hinge zone $\rightarrow$ limb or hanging wall $\rightarrow$ fault plane $\rightarrow$ footwall) according to the development and characteristics of the structure. Since the coal seam deposits at the B1 anticline is thin, the F10 normal fault is generated near the hinge zone of the anticline under tensile stress, so monitoring lines are arranged every $60 \mathrm{~m}$ from the $\mathrm{B} 1$ anticline limb to the hinge zone, F10 fault plane, and fault plane to the anticline limb, respectively (Figure 6).

Figures 7-Figure 8 show the characteristics of the changes of CBM content, coal reservoir pressure, temperature, and permeability from the 1 st $\mathrm{d}$ to the 150 th $\mathrm{d}$ of different structure types. The CBM content and coal reservoir pressure in the syncline area gradually increase as the working face advances, and the values stabilize after about $100 \mathrm{~d}$, 


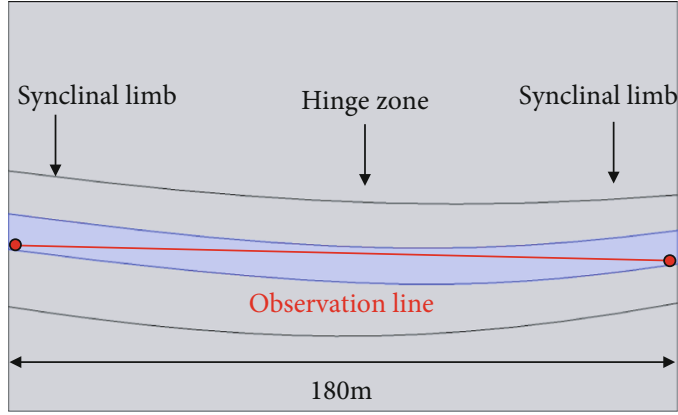

(a)

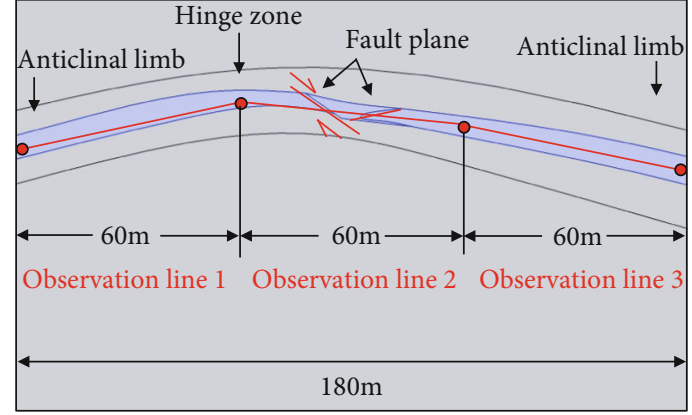

(b)

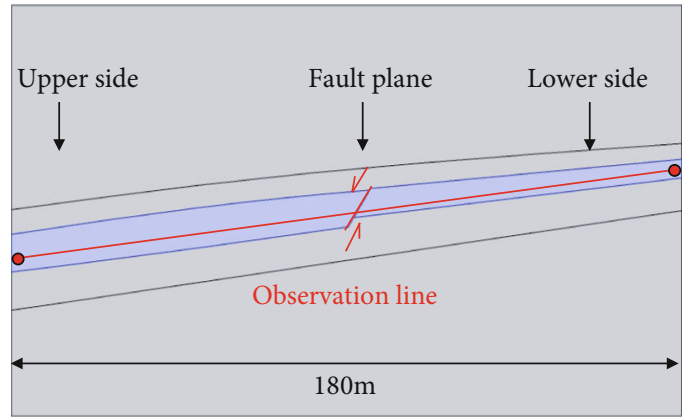

(c)

FIGURE 6: Location of monitoring lines near different structural sites: (a) X3 syncline monitoring line; (b) B1 anticline and F10 fault monitoring lines; (c) F11 fault monitoring line.

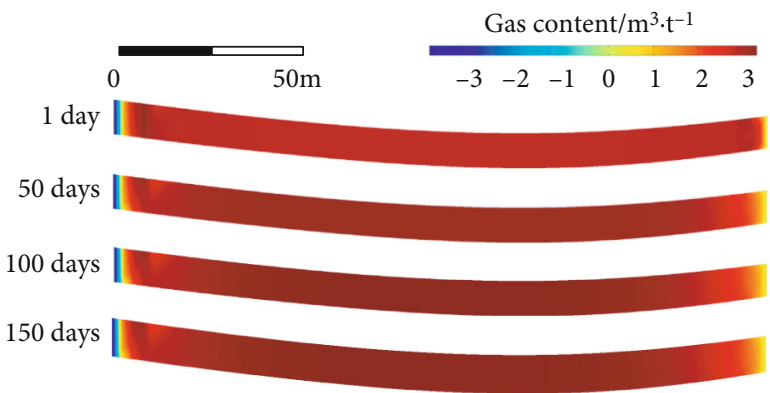

(a)

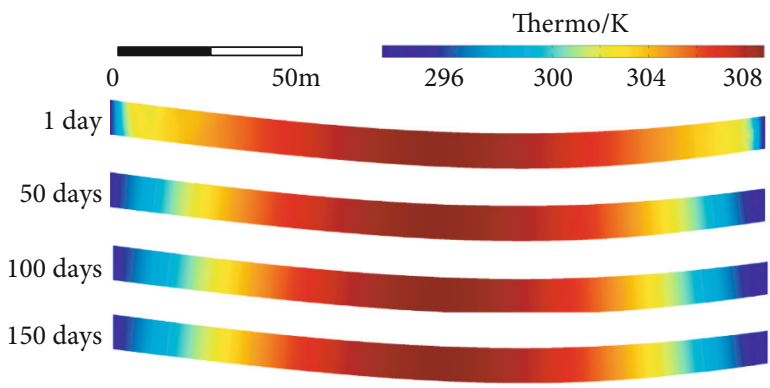

(c)

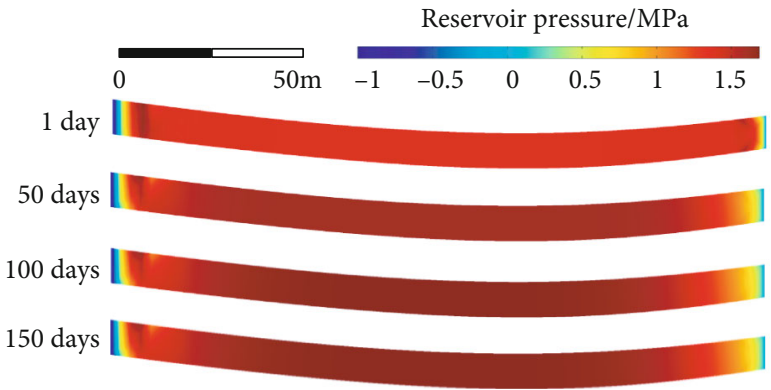

(b)

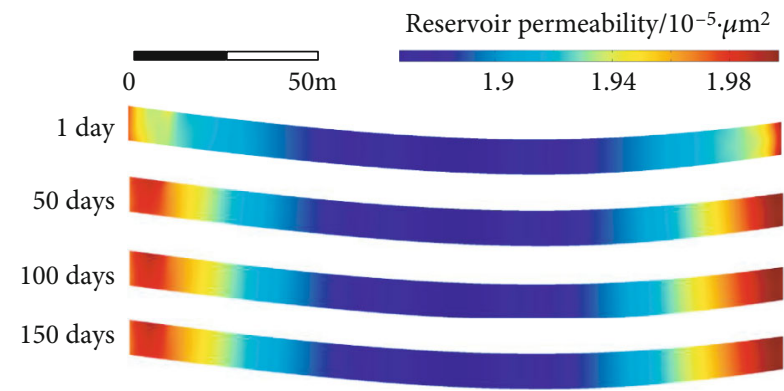

(d)

FIgURE 7: Multifield evolutionary characteristics of THM near the X3 syncline structure.

and the hinge zone shows obvious advantage of pressureholding reservoir formation (Figures 7(a), 8(a), and 9(a)). The coal reservoir temperature in the syncline hinge zone is higher and the permeability is lower, and the range of the high-temperature zone and low-permeability zone in the hinge zone gradually decreases with time change, and the change range tends to be stable around $100 \mathrm{~d}$. Near the tectonic combination of the B1 anticline and F10 normal fault, the characteristics of coal reservoir pressure and coalbed gas content changes are consistent and synchronous, and the pressure and gas content of the anticline hinge zone are lower (Figure 8). The coal reservoir pressure is low due to 


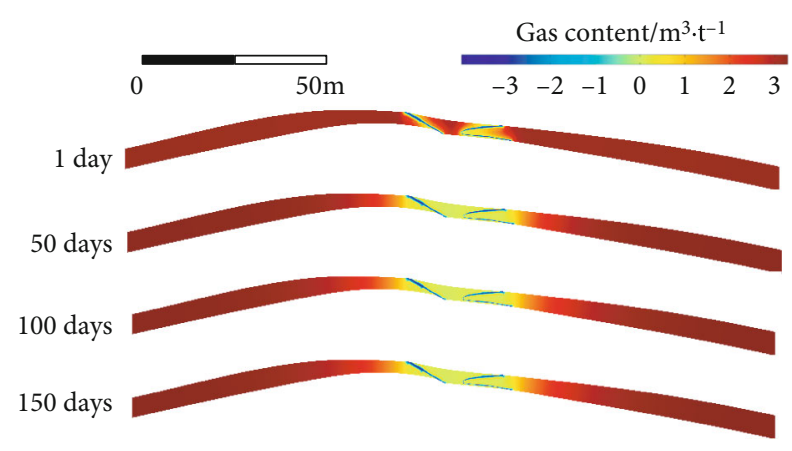

(a)

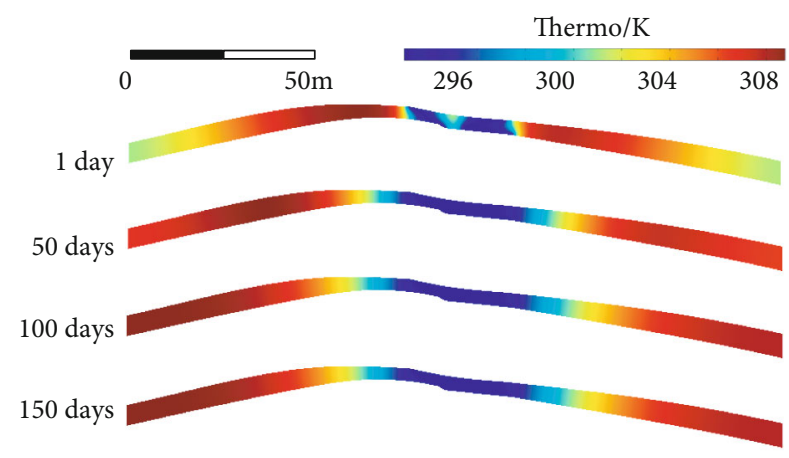

(c)

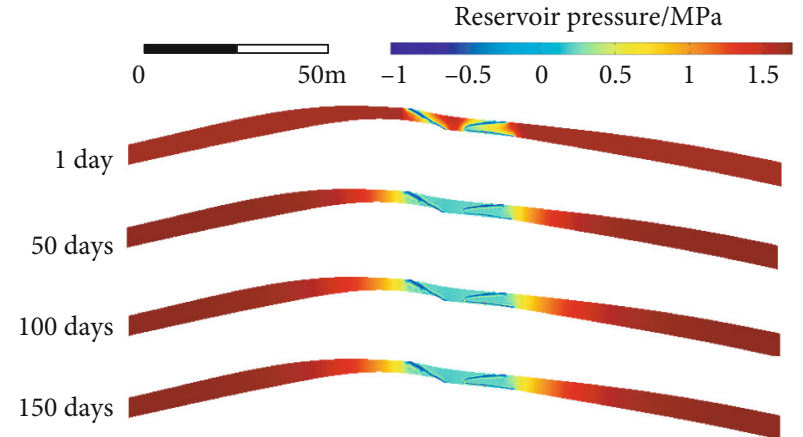

(b)

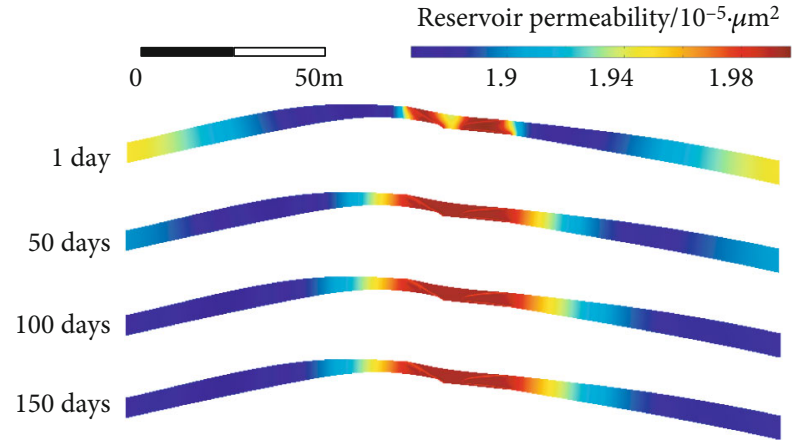

(d)

FIGURE 8: Multifield evolutionary characteristics of THM near B1 anticline and F10 normal fault structures.

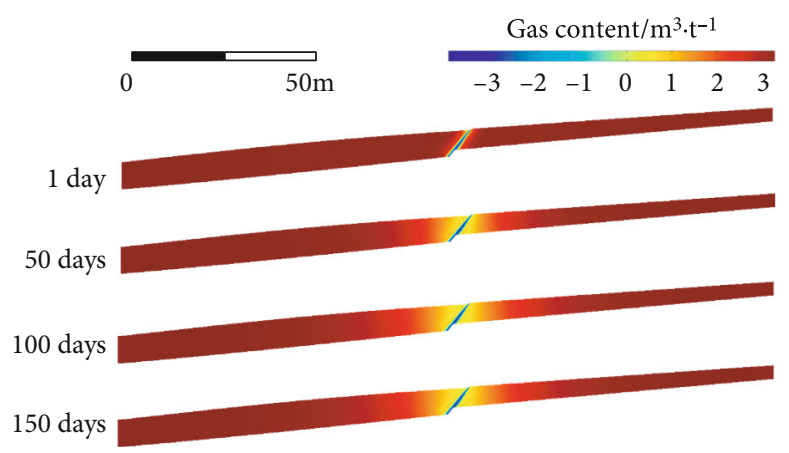

(a)

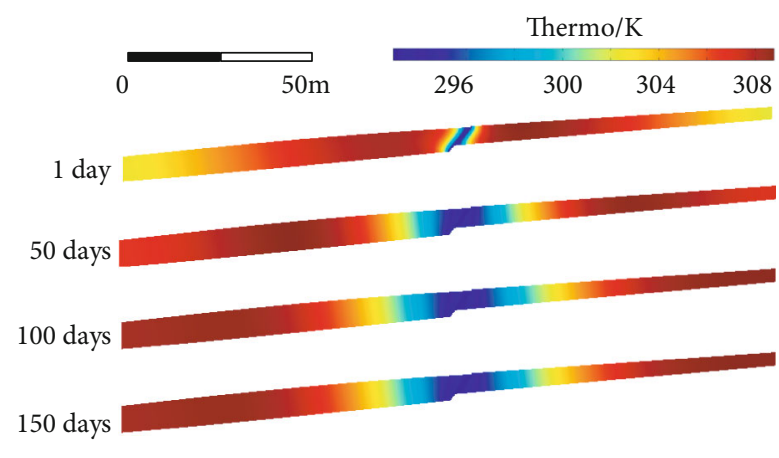

(c)

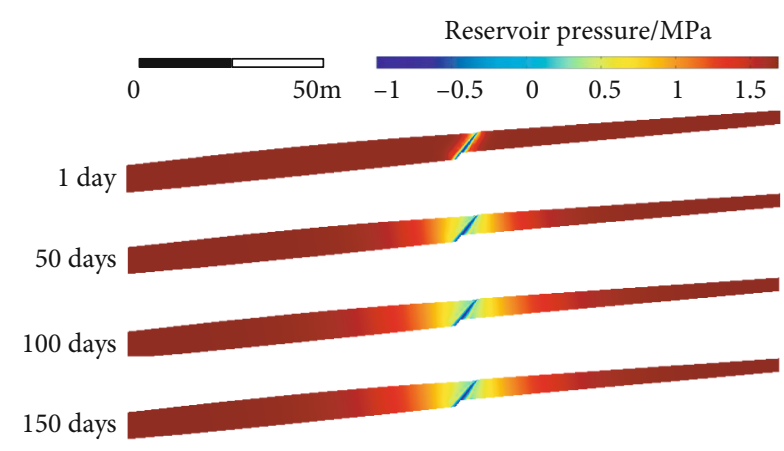

(b)

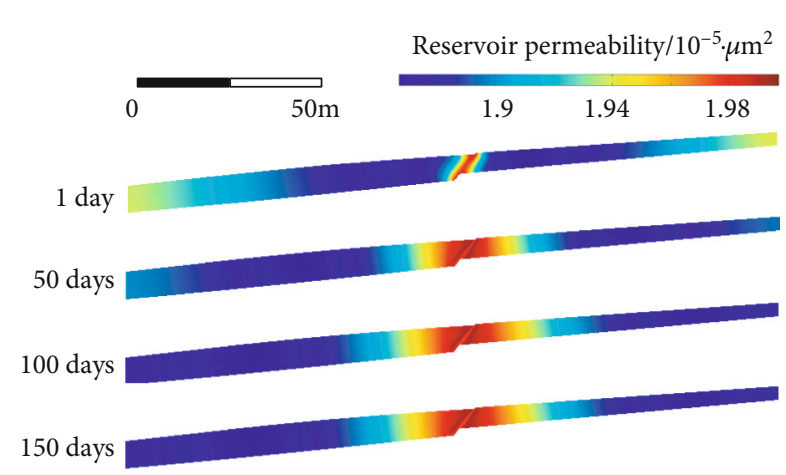

(d)

FIGURE 9: Multifield evolutionary characteristics of THM near the F11 normal fault structure. 

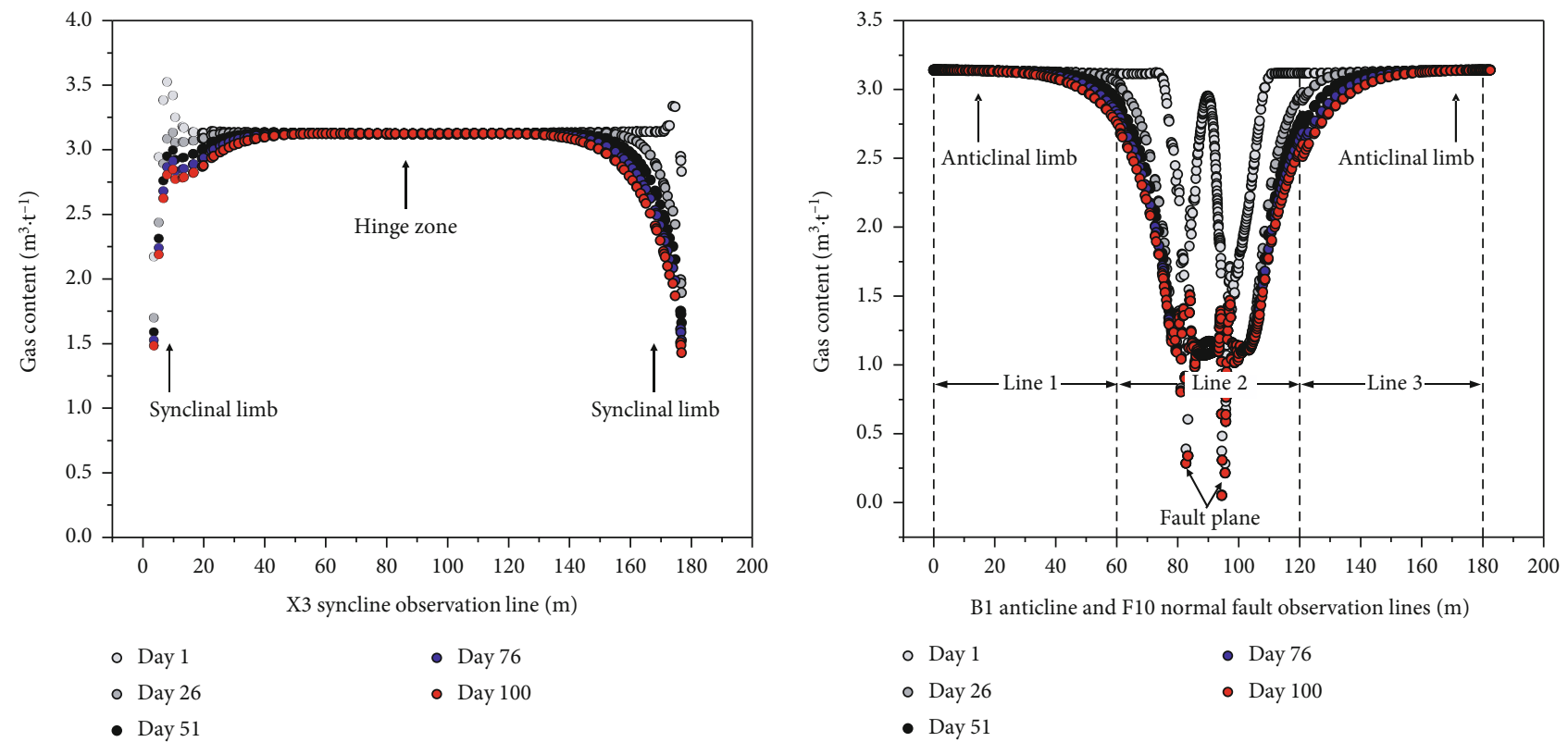

(a)

(b)

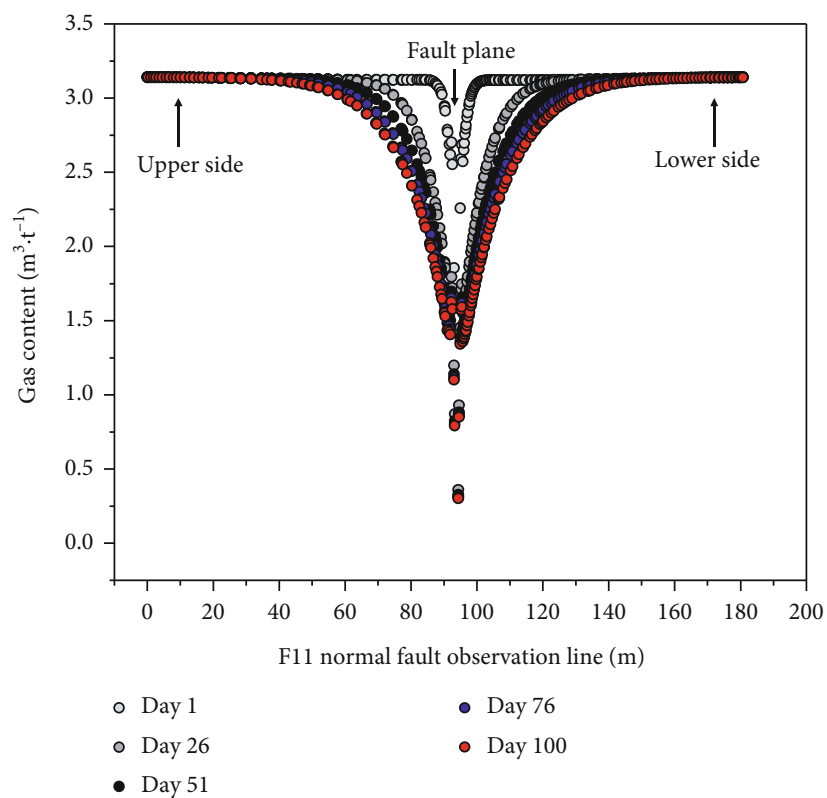

(c)

FIGURE 10: Variation of CBM content near different tectonic types: (a) variation of CBM content near the X3 syncline structure; (b) variation of CBM content near the B1 anticline and F10 normal fault structure; (c) variation of methane content near the F11 normal fault structure.

the development of fractures near the two fault planes of the F10 normal fault, and the coal reservoir permeability increases while the coalbed gas is dispersed. With the change of time, the range of change of coalbed methane content, coal reservoir pressure, temperature, and permeability near the fault plane gradually expands and stabilizes after about $100 \mathrm{~d}$ (Figure 9). Near the F11 normal fault, the CBM content, coal reservoir pressure, temperature, and permeability change in value and influence range with the advance of the working face and stabilize after about $100 \mathrm{~d}$. Near the fault plane, the coal seam gas content and coal reservoir pressure are lower under tensile stress, while the coal matrix is more continuous near the upper and footwall of the fault, which gradually has the advantage of gas richness into the reservoir with time. The coal reservoir temperature varies relatively large in different parts, and the change trend is consistent with the coal reservoir pressure as a whole. Due to the development of fault plane fractures, the permeability of the coal reservoir is significantly increased, and the range of the high-permeability zone near the fault plane gradually expands with the change of time and stabilizes after $100 \mathrm{~d}$.

In order to further analyze the change process of CBM content near the syncline, anticline, and fault in different tectonic parts, the data statistics of interpolation value selected 


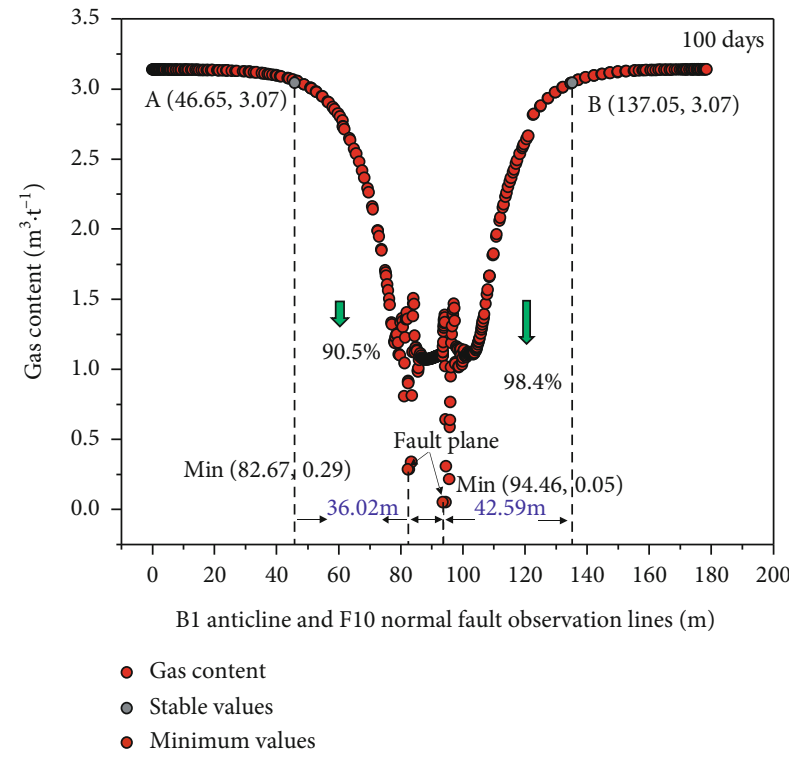

(a)

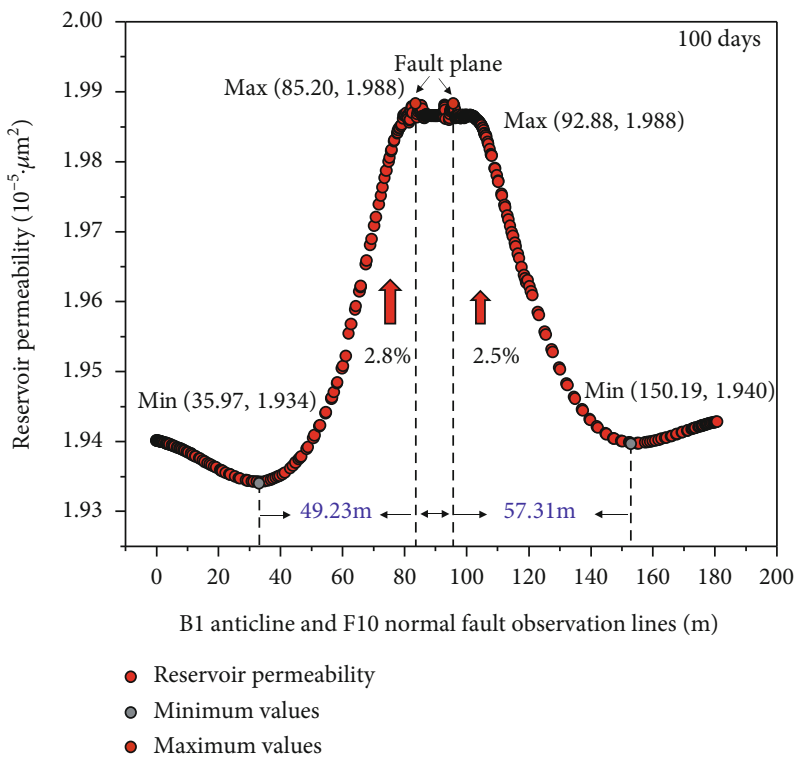

(c)

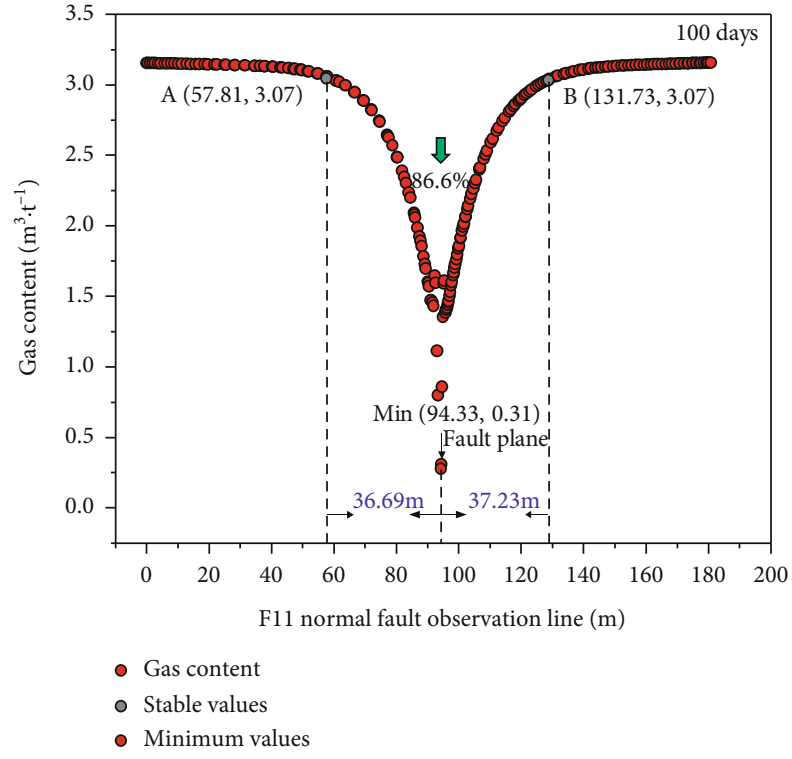

(b)

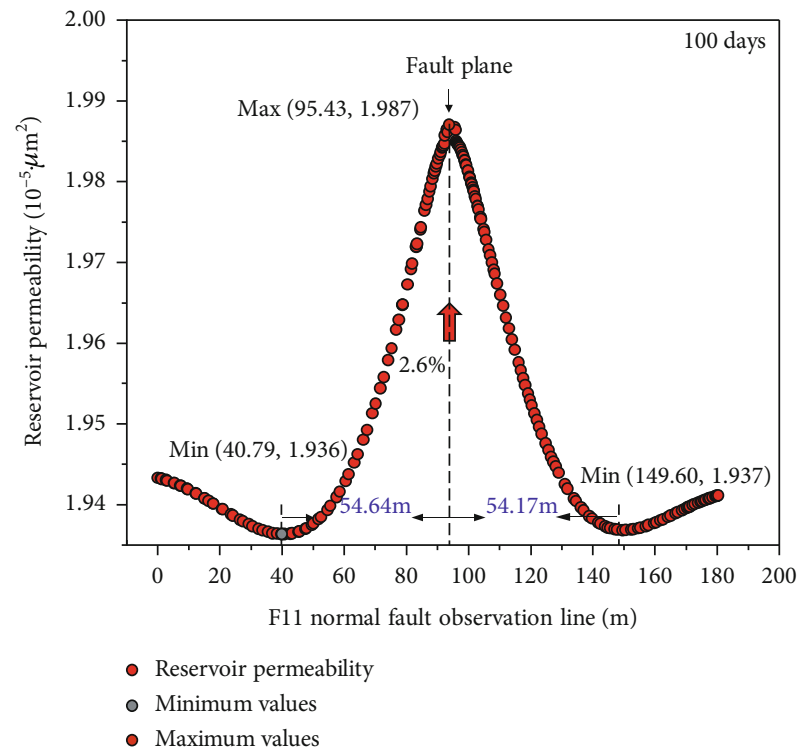

(d)

FIgURE 11: Variation of gas content and permeability of coal reservoirs near different tectonic positions: (a) variation of coalbed gas content near the B1 anticline and F10 normal fault; (b) variation of coalbed gas content near the F11 normal fault; (c) variation of permeability of the coal reservoir near the B1 anticline and F10 normal fault; (d) change in permeability of the coal reservoir near the F11 normal fault.

starting from the 1 st $\mathrm{d}$, interval $25 \mathrm{~d}$, and end point $100 \mathrm{~d}$ were statistically obtained to plot the results of CBM thermal-hydraulic-mechanical coupling evolution near different types of tectonics in the 1302 working face from 1 to $100 \mathrm{~d}$ time (as Figure 10 shows).

According to the change of gas content of the no. 3 coal reservoir in working face 1302 shown in Figure 10, it can be seen that the change of CBM content in different structural parts is different and the CBM content in the limb of the $\mathrm{X} 3$ gentle dip syncline is lower, but the hinge zone has the advantage of holding pressure and the CBM content is higher (Figure 10(a)). In the process of changing from limb-hinge zone-limb part, the CBM content shows a wide and slow arc-shaped trend of increasing and then decreasing, and the change of CBM content near the B1 anticline and F10 normal fault is relatively complicated. The CBM content in the direction of the hinge zone from the limb of the anticline gradually decreases, and the CBM content gradually decreases and falls below $0.5 \mathrm{~m}^{3} / \mathrm{t}$ at each of the two fault planes of the F10 normal fault and then gradually increases along the hinge zone of the anticline to form a near funnel-shaped curve with the east limb of the anticline (Figure 10(b)). Along the monitoring line of the F11 fault, from hanging wall-fault, the CBM content of the F11 fault is funnel-shaped along the monitoring line from hanging wall-fault plate-footwall and decreases significantly at the normal fault plane (Figure 10(c)). 
Comprehensive analysis of the data in Figures 7-10 shows that the gas content, reservoir pressure, temperature, and permeability vary nonlinearly in different tectonic sites. In the anticline hinge zone, the coal seam is thin and prone to fracture under tension force, and the internal fractures of the coal matrix is more developed, resulting in lower pressure and temperature of the coal reservoir, lower gas content, and higher permeability of the corresponding coal reservoir. The changes of coal seam gas content, reservoir pressure, and temperature in the thick coal seam part of the syncline hinge zone show the advantages of reservoir formation of pressure maintenance, heat preservation, and gas enrichment. Therefore, the gas-rich advantage of the syncline hinge zone and the gas-poor characteristic of the anticline hinge zone are mainly characterized by the wide and slow arc-shaped change of coalbed gas content. The CBM content near the normal fault shows a funnel-shaped trend, with the fault plane being the lowest point and the hanging wall and footwall decreasing toward the fault plane, respectively. In summary, the gentle dip syncline hinge zone is rich in gas with heat preservation and low permeability, while the gentle dip anticline hinge zone is poor in gas with low temperature and low pressure and high permeability, and the small normal fault within the layer shows the funnel-type gas control characteristics. The syncline hinge zone is a gas accumulation zone, and the fault plane of the normal fault is a highpermeability area of the reservoir.

4.2. Variation Distance of Gas Content and Reservoir Permeability Controlled by Tectonism. Statistical analysis of the changes in gas content and permeability of coal reservoirs near different tectonic sites is shown in Figure 11. The coal seam gas content and coal reservoir permeability changes are complicated near the normal fault because the coal seam forms fissures under the condition of the tensional tectonic stress field. The normal fault developed within the coal seam has a small drop and does not extend to the top and bottom plates. The coal seam at the fault plane is misfractured or generates a fracture plane causing CBM dissipation while increasing the permeability of the coal reservoir.

In Figure 11(a), the CBM content of B1 anticline and F10 normal fault parts reached the minimal value at two fault planes with coordinates of $(82.67,0.29)$ and $(94.46,0.05)$, respectively, and the $\mathrm{CBM}$ content tends to be stable in $\mathrm{A}$ $(46.65,3.07)$ and $B(137.05,3.07)$ toward the anticline limbs, respectively. The fault plane is $36.02 \mathrm{~m}$ and $42.59 \mathrm{~m}$ from points $\mathrm{A}$ and $\mathrm{B}$, respectively, and the gas content decreases by $90.5 \%$ and $98.4 \%$, respectively, indicating that the tectonic combination of the B1 anticline and F10 normal fault, whose gas control range is $36.02 \mathrm{~m} \sim 42.59 \mathrm{~m}$ from the fault plane. The CBM content of the F11 normal fault reaches a very small value at the fault plane $(94.50,0.41)$, which is $86.6 \%$ lower than the stable point of CBM content $\mathrm{A}$ and $\mathrm{B}$, and the distance is $36.69 \mathrm{~m}$ and $37.23 \mathrm{~m}$, respectively, indicating that the gas control range of the F11 normal fault is $37 \mathrm{~m}$ (Figure 11(b)). The above analysis shows that the CBM content in different parts of the small normal fault developed in the layer shows a funnel-shaped trend of first decreasing and then increasing, the CBM content reaches a minimal value at the fault plane, and the CBM content significantly decreases within $37 \mathrm{~m}$ of the two disks of the fault plane, with a decrease of $86 \%$. The CBM content gradually tends to level off after moving away from the influence range of the fault plane.

The continuity of the coal matrix near the fault plane of the normal fault is destroyed, and the coalbed gas content is reduced while a large number of fractures are developed, which makes the permeability of the coal reservoir increase. According to Figure 11(c), the permeability near the F10 normal fault is affected by the B1 anticline tectonics, and the overall trend of slow decline-sharp increase-small fluctuation-sharp decline-slow increase is shown. At the two fault plane locations, the permeability reaches a great value of $1.988 \times 10^{-5} \mu \mathrm{m}^{2}$ with an increase of $2.8 \%$ and $2.5 \%$, respectively, and the distance minima are $49.23 \mathrm{~m}$ and $57.23 \mathrm{~m}$, respectively. The permeability of the F11 normal fault shows a trend of slowly decreasing-sharply increasing-sharply decreasing-slowly increasing in different structural parts. At the fault plane, the permeability reaches a great value of $1.988 \times 10^{-5} \mu \mathrm{m}^{2}$, and the permeability increases by $2.6 \%$, and the distance minima are $54.6 \mathrm{~m}$ and $54.17 \mathrm{~m}$, respectively (Figure 11(d)). From the above analysis, the permeability of the small normal fault developed in the layer is characterized by single-peak variation, the highest increase in permeability near the fault plane is about $2.6 \%$, and the influence range is about $54 \mathrm{~m}$ for both walls of the fault plane.

\section{Conclusion}

In this study, the actual geological structure of the Guojiahe wellfield in the Yonglong mining area was used as the background, and the THM coupling model was used to analyze the variation law of CBM content and permeability in anticline, syncline, and normal fault tectonic sites and to reveal the variation distance of gas content and reservoir permeability controlled by tectonism in different tectonic positions. The main findings are as follows.

(1) The CBM content changes in different tectonic parts are different. The CBM content in the $\mathrm{X} 3$ gentle dip syncline limb is low, but the hinge zone has the advantage of pressure maintenance, and the CBM content is high. In the process of changing from the limb-hinge zone to the limb, the CBM content shows a wide and slow arc-shaped trend of increasing and then decreasing, and the CBM content changes near the $\mathrm{B} 1$ anticline and F10 normal fault are relatively complicated

(2) The methane content of the anticline limb gradually decreases toward the hinge zone and drops below $0.5 \mathrm{~m}^{3} / \mathrm{t}$ at each of the two fault planes of the $\mathrm{F} 10$ normal fault, and then, the methane content gradually increases along the anticline hinge zone to form a near funnel-shaped curve with the east limb of the anticline. The CBM content of the F11 fault gradually increases along the anticline hinge zone and forms a 
near funnel-shaped curve with the east limb of the anticline; along the monitoring line from hanging wall-fault plane-footwall, the overall CBM content shows a funnel-shaped trend and decreases significantly at the normal fault plane

(3) The hinge zone of the gentle dip syncline is gas-rich with low permeability, pressure maintenance, and thermal insulation, while the hinge zone of the gentle dip anticline is gas-poor with low temperature, low pressure, and high permeability. The gas accumulation zone is in the thick coal seam zone of the syncline, and the fault plane of the normal fault is near the high-permeability area of CBM. Within the Guojiahe wellfield, the variation distance of gas content and reservoir permeability controlled by tectonism is $37 \mathrm{~m}$ and $54 \mathrm{~m}$ from the fault plane, respectively

\section{Data Availability}

The experiment data used to support the findings of this study are included within the article.

\section{Conflicts of Interest}

The authors declare that they have no conflicts of interest.

\section{Acknowledgments}

This study was supported by the National Natural Science Foundation of China (Approval No. 41502160), the Shaanxi Technical Innovation Guidance Project (Approval No. 2019 CGHJ-20), and the Open Research Fund Program of State key Laboratory of Hydroscience and Engineering (sklhse2021-C-02).

\section{References}

[1] C. Ou, C. Li, D. Zhi, L. Xue, and S. Yang, "Coupling accumulation model with gas-bearing features to evaluate low-rank coalbed methane resource potential in the southern Junggar Basin, China," AAPG Bulletin, vol. 102, no. 1, pp. 153-174, 2018.

[2] S. Hou, X. Wang, X. Wang, Y. Yuan, X. Zhuang, and X. Wang, "Geological controls on gas saturation in the Yanchuannan coalbed methane field, southeastern Ordos Basin, China," Marine and Petroleum Geology, vol. 78, pp. 254-270, 2016.

[3] Y. Li, D. Z. Tang, P. Wu et al., "Continuous unconventional natural gas accumulations of Carboniferous-Permian coalbearing strata in the Linxing area, northeastern Ordos basin, China," Journal of Natural Gas Science and Engineering, vol. 36, pp. 314-327, 2016.

[4] O. Esen, S. C. Özer, A. Soylu, A. Ramazani Rend, and A. Fişne, "Geological controls on gas content distribution of coal seams in the Kını coalfield, Soma Basin, Turkey," International Journal of Coal Geology, vol. 231, article 103602, 2020.

[5] M. Li, B. Jiang, Q. Miao, G. Wang, Z. You, and F. Lan, "Multiphase tectonic movements and their controls on coalbed methane: a case study of no. 9 coal seam from eastern Yunnan, SW China," Energies, vol. 13, no. 22, 2020.
[6] L. F. Ruppert, J. C. Hower, R. T. Ryder, J. R. Levine, M. H. Trippi, and W. C. Grady, "Geologic controls on thermal maturity patterns in Pennsylvanian coal-bearing rocks in the Appalachian Basin," International Journal of Coal Geology, vol. 81, no. 3, pp. 169-181, 2010.

[7] Y. Yuan, Y. Shan, Y. Tang, and D. Cao, "Coalbed methane enrichment regularity and major control factors in the Xishanyao Formation in the western part of the southern Junggar Basin," Acta Geologica Sinica - English Edition, vol. 94, no. 2, pp. 485-500, 2020.

[8] Z. Zhang, Y. Qin, T. Yi, Z. You, and Z. Yang, "Pore structure characteristics of coal and their geological controlling factors in eastern Yunnan and western Guizhou, China," ACS Omega, vol. 5, no. 31, pp. 19565-19578, 2020.

[9] X. W. Hou, S. M. Liu, Y. M. Zhu, and Y. Yang, "Evaluation of gas contents for a multi-seam deep coalbed methane reservoir and their geological controls: in situ direct method versus indirect method," Fuel, vol. 265, article 116917, 2020.

[10] Y. J. Lu, D. M. Liu, Y. D. Cai, Q. Li, and Q. Jia, "Pore-fractures of coalbed methane reservoir restricted by coal facies in Sangjiang-Muling coal-bearing basins, Northeast China," Energies, vol. 13, no. 5, 2020.

[11] C. Guo, Y. Qin, D. Ma, and L. Lu, "Pore structure response of sedimentary cycle in coal-bearing strata and implications for independent superposed coalbed methane systems," Energy Sources Part a-Recovery Utilization and Environmental Effects, vol. 42, pp. 1-20, 2020.

[12] Z. N. Ye, E. K. Hou, Z. H. Duan, and Z. Li, "Coal reservoir characterization in a tectonic setting and the effects of tectonism on the coalbed methane (CBM) content," Advances in Materials Science and Engineering, vol. 2019, Article ID 7974628, 11 pages, 2019.

[13] H. Sun, X. L. Liu, and J. B. Zhu, "Correlational fractal characterisation of stress and acoustic emission during coal and rock failure under multilevel dynamic loading," International Journal of Rock Mechanics and Mining Sciences, vol. 117, pp. 1-10, 2019.

[14] H. Han, S. Liang, Y. Liang et al., "The role of coal mechanical characteristics on reservoir permeability evolution and its effects on $\mathrm{CO} 2$ sequestration and enhanced coalbed methane recovery," Geofluids, vol. 2020, Article ID 8842309, 28 pages, 2020.

[15] C. G. Li, B. Jiang, W. Ju, G. Cheng, and Y. Song, "Characteristics of tectonic deformation in the Daning-Jixian region, eastern Ordos Basin: implications for the exploration and development of coalbed methane," Energy Exploration \& Exploitation, vol. 37, no. 3, pp. 907-921, 2019.

[16] J. L. Zhao, D. Z. Tang, W. J. Lin, Y. Qin, and H. Xu, "In-situ stress distribution and its influence on the coal reservoir permeability in the Hancheng area, eastern margin of the Ordos Basin, China," Journal of Natural Gas Science and Engineering, vol. 61, pp. 119-132, 2019.

[17] K. Z. Zhang, L. Wang, Y. P. Cheng et al., "Geological control of fold structure on gas occurrence and its implication for coalbed gas outburst: case study in the Qinan coal mine, Huaibei coalfield, China," Natural Resources Research, vol. 29, no. 2, pp. 1375-1395, 2020.

[18] Q. Wang, X. B. Su, L. N. Su, and F. Zhou, "CBM geological characteristics and exploration potential in the Sunan syncline block, southern north China basin," Journal of Petroleum Science and Engineering, vol. 186, article 106713, 2020. 
[19] H. Wang, Y. B. Yao, D. M. Liu, Z. Pan, Y. Yang, and Y. Cai, "Fault-sealing capability and its impact on coalbed methane distribution in the Zhengzhuang field, southern Qinshui Basin, North China," Journal of Natural Gas Science and Engineering, vol. 28, pp. 613-625, 2016.

[20] J. Yan, T. Jia, G. Wei, M. Zhang, and Y. Ju, "In-situ stress partition and its implication on coalbed methane occurrence in the basin-mountain transition zone: a case study of the Pingdingshan coalfield, China," Sädhanā, vol. 45, no. 1, 2020.

[21] Y. du, C. Q. Fu, Z. J. Pan et al., "Geochemistry effects of supercritical $\mathrm{CO}_{2}$ and $\mathrm{H}_{2} \mathrm{O}$ on the mesopore and macropore structures of high- rank coal from the Qinshui Basin, China," International Journal of Coal Geology, vol. 223, article 103467, 2020.

[22] Z. T. Zhang, R. Zhang, S. Y. Wu, J. Deng, Z. Zhang, and J. Xie, "The stress sensitivity and porosity sensitivity of coal permeability at different depths: a case study in the Pingdingshan mining area," Rock Mechanics and Rock Engineering, vol. 52, no. 5, pp. 1539-1563, 2019.

[23] L. Qin, C. Zhai, J. Z. Xu, S. Liu, C. Zhong, and G. Yu, "Evolution of the pore structure in coal subjected to freeze-thaw using liquid nitrogen to enhance coalbed methane extraction," Journal of Petroleum Science and Engineering, vol. 175, pp. 129-139, 2019.

[24] Y. D. Cai, D. M. Liu, Z. H. Liu, Y. F. Zhou, and Y. Che, "Evolution of pore structure, submaceral composition and produced gases of two Chinese coals during thermal treatment," Fuel Processing Technology, vol. 156, pp. 298-309, 2017.

[25] Z. H. Qu, G. G. X. Wang, B. Jiang, V. Rudolph, X. Dou, and $\mathrm{M}$. $\mathrm{Li}$, "Experimental study on the porous structure and compressibility of tectonized coals," Energy \& Fuels, vol. 24, no. 5, pp. 2964-2973, 2010.

[26] Z. N. Ye, E. K. Hou, and Z. H. Duan, "Micrometer-scale pores and fractures in coals and the effects of tectonic deformation on permeability based on fractal theory," AIP Advances, vol. 10 , no. 2,2020 .

[27] Z. Li, H. X. Liu, Z. L. Dun, L. Ren, and J. Fang, "Grouting effect on rock fracture using shear and seepage assessment," Construction and Building Materials, vol. 242, article 118131, 2020.

[28] X. Yan, S. Zhang, S. Tang et al., "Quantitative optimization of drainage strategy of coalbed methane well based on the dynamic behavior of coal reservoir permeability," Scientific Reports, vol. 10, no. 1, article 20306, 2020.

[29] X. Wang, J. Pan, K. Wang, T. Ge, J. Wei, and W. Wu, "Characterizing the shape, size, and distribution heterogeneity of porefractures in high rank coal based on X-ray CT image analysis and mercury intrusion porosimetry," Fuel, vol. 282, article 118754, 2020.

[30] M. Cheng, X. Fu, and J. Kang, "Compressibility of different pore and fracture structures and its relationship with heterogeneity and minerals in low-rank coal reservoirs: an experimental study based on nuclear magnetic resonance and micro-CT," Energy \& Fuels, vol. 34, no. 9, pp. 10894-10903, 2020.

[31] Q. Li, D. Liu, Y. Cai, B. Zhao, Y. Qiu, and Y. Zhou, "Scale-span pore structure heterogeneity of high volatile bituminous coal and anthracite by FIB-SEM and X-ray $\mu$-CT," Journal of Natural Gas Science and Engineering, vol. 81, p. 103443, 2020.

[32] B. Zhang, X. Fu, Z. Deng, and M. Hao, "Characterization of pore structure and its relationship with methane adsorption on medium-high volatile bituminous coal: an experimental study using nuclear magnetic resonance," Journal of
Nanoscience and Nanotechnology, vol. 21, no. 1, pp. 515-528, 2021.

[33] H. Sun, X. L. Liu, S. G. Zhang, and K. Nawnit, "Experimental investigation of acoustic emission and infrared radiation thermography of dynamic fracturing process of hard-rock pillar in extremely steep and thick coal seams," Engineering Fracture Mechanics, vol. 226, p. 106845, 2020.

[34] Z. Li, S. G. Liu, W. T. Ren, J. Fang, Q. Zhu, and Z. Dun, "Multiscale laboratory study and numerical analysis of waterweakening effect on shale," Advances in Materials Science and Engineering, vol. 2020, Article ID 5263431, 14 pages, 2020.

[35] J. Huang, Z. Song, Z. Liao, W. Zhao, and D. Wang, "Quantification of cracks and the evolution of permeability for reservoir rock under coupled THM: equipment development and experimental research," Geomechanics and Geophysics for GeoEnergy and Geo-Resources, vol. 6, no. 4, 2020.

[36] N. Fan, J. R. Wang, C. B. Deng, Y. Fan, Y. Mu, and T. Wang, "Numerical study on enhancing coalbed methane recovery by injecting N2/CO2 mixtures and its geological significance," Energy Science \& Engineering, vol. 8, no. 4, pp. 1104-1119, 2020.

[37] N. Fan, J. Wang, C. Deng, Y. Mu, and Y. Fan, "Coalbed methane extraction in multibranch horizontal wells: evolutions of reservoir characteristics with different geometric parameters," Energy Sources, Part A: Recovery, Utilization, and Environmental Effects, vol. 41, pp. 1-16, 2019.

[38] Q. Meng, H. Wang, M. Cai, W. Xu, X. Zhuang, and T. Rabczuk, "Three-dimensional mesoscale computational modeling of soil-rock mixtures with concave particles," Engineering Geology, vol. 277, article 105802, 2020.

[39] Z. G. Tao, C. Zhu, M. C. He, and M. Karakus, "A physical modeling-based study on the control mechanisms of negative Poisson's ratio anchor cable on the stratified toppling deformation of anti- inclined slopes," International Journal of Rock Mechanics and Mining Sciences, vol. 138, p. 104632, 2021.

[40] Y. Wang, B. Zhang, S. H. Gao, and C. H. Li, "Investigation on the effect of freeze-thaw on fracture mode classification in marble subjected to multi-level cyclic loads," Theoretical and Applied Fracture Mechanics, vol. 111, article 102847, 2021. 